\title{
A roadmap framework for solar aided power generation in South Africa
}

\author{
Josephine K Musango* \\ School of Public Leadership, and the Centre for Renewable and Sustainable Energy Studies, Stellenbosch \\ University, South Africa
}

\begin{abstract}
Alan C Brent
Department of Industrial Engineering, and the Centre for Renewable and Sustainable Energy Studies, Stellenbosch University, South Africa
\end{abstract}

\begin{abstract}
Technology roadmaps are critical for decisions pertaining to technology development. They have been utilised in the renewable energy sector to assist in filtering alternative technology options in order to support energy policy formulation, energy security and energy independence, among others. However, solar aided power generation is a recent concept and no roadmap has been developed for the technology as yet. This paper thus reviewed the literature related to roadmapping with the aim of understanding the methods and tools that have been utilised in other settings. Informed by the literature, a conceptual framework was developed, which was further utilised for the initial analysis for developing a roadmap for solar aided power generation in South Africa. Generally, it would be beneficial for South Africa to integrate solar aided power generation within its current Renewable Energy Independent Power Producer Procurement Programme (REIPPPP) or the National Treasury Public-Private Partnership (PPP) programme. However, it should be noted that this is only feasible in the short- and medium-term. In the long-term, there is a need to support stand-alone solar thermal technologies.
\end{abstract}

Keywords: technology roadmapping, solar aided power generation, renewable energy policy South Africa

\footnotetext{
${ }^{*}$ Corresponding author:

josephine.musango@spl.sun.ac.za
}

\section{Introduction}

Recent technological advancement has necessitated industry, companies and governments to seek for approaches to align their strategic objectives with these advances. One of these approaches is roadmapping, which was utilised as early as the 1950's (Amer and Daim, 2010), but formally developed by Motorola in the 1970's as an approach to support product technology planning in an integrated manner (Carvalho et al., 2013). It is regarded as a flexible strategic planning approach that allows for integrating business and technology. Various studies have provided definitions of roadmaps. According to Galvin (1998), a roadmap is 'an extended look at the future of a chosen field of inquiry composed from the collective knowledge and imagination of the brightest drivers of the change'. Similarly, Winebrake (2003) defines a technology roadmap as a 'future based strategic planning [tool] that outlines goals, barriers and strategies necessary for achieving a given vision of technological advancement and market penetration'. Since its development, it has been widely used by other companies, industries, as well as countries (Amer and Daim, 2010). It has also been utilised in the renewable energy sector, to assist in filtering alternative technology options in order to support energy policy formulation, energy security and energy independence, among others (Amer and Daim, 2010).

Roadmapping consists of two main components: the roadmapping process, which is generally the application; and the roadmap, which is the output of the application (Carvalho et al., 2013). Roadmaps are useful in answering three key questions, as summarised in Table 1. Generally, the visioning question, of 'where we want to go', comes first and determines what will be relevant in the present (Kamtsiou, 2014). These questions can further be represented in a framework - as shown in 
Table 1: Fundamental questions for an effective roadmap

Source: adapted from Carvalho et al. (2013) and Phaal and Muller (2009)

\begin{tabular}{ll}
$\begin{array}{l}\text { Question } \\
\text { Where are we going? }\end{array}$ & $\begin{array}{l}\text { This represents the vision, mission, objectives, goals and targets that the roadmap will be } \\
\text { achieving. }\end{array}$ \\
\hline Where are we now? & $\begin{array}{l}\text { This represents the current state of technology development, products and market } \\
\text { development. }\end{array}$ \\
\hline How can we get there? This represents the policy measures, action plans, research and development programs and \\
strategies (both long- and short-term) that need to be implemented to achieve the vision, \\
goals, objectives.
\end{tabular}

Figure 1. The 'where to' question tends to be a qualitative focus while the 'what now' question has a quantitative focus.

Generally, there is no standardized approach, methods and tools for developing a roadmap in the public domain; and most of the individual company roadmaps are fragmented and inaccessible (Amer and Daim, 2010). Amer and Daim (2010), however, recommend that the overall goal and objective of a roadmap should guide the choice of an appropriate method and approach to develop a roadmap.

This paper therefore reviewed the literature and identified the approaches, methods and tools that have been utilised in roadmapping. This informed the development of the conceptual framework and the choice of the approaches that were utilised for facilitating integration of solar aided power generation within South African energy policy. Solar aided power generation involves the integration of solar thermal and fossil fuel plant technology in order to account for the environmental benefit of the renewable energy technology and the scale, efficiency and reliability of the fossil fuel technology (Pierce et al., 2013).

The paper is organised in five sections. Section 2 reviews the literature on the approaches and methods for developing a roadmap. Section 3 uses the literature review to develop a conceptual framework that was applied to provide the initial analysis for the roadmapping of solar aided power generation technology. Section 4 then presents the solar aided power generation case study and the analysis undertaken. Finally, Section 5 presents conclusions and recommendations for integrating solar aided power generation in South Africa.

\section{Literature review}

\subsection{Overview of roadmaps}

Within the field of technology management, roadmapping has proved to be a useful tool for strategic and operational decision-making and

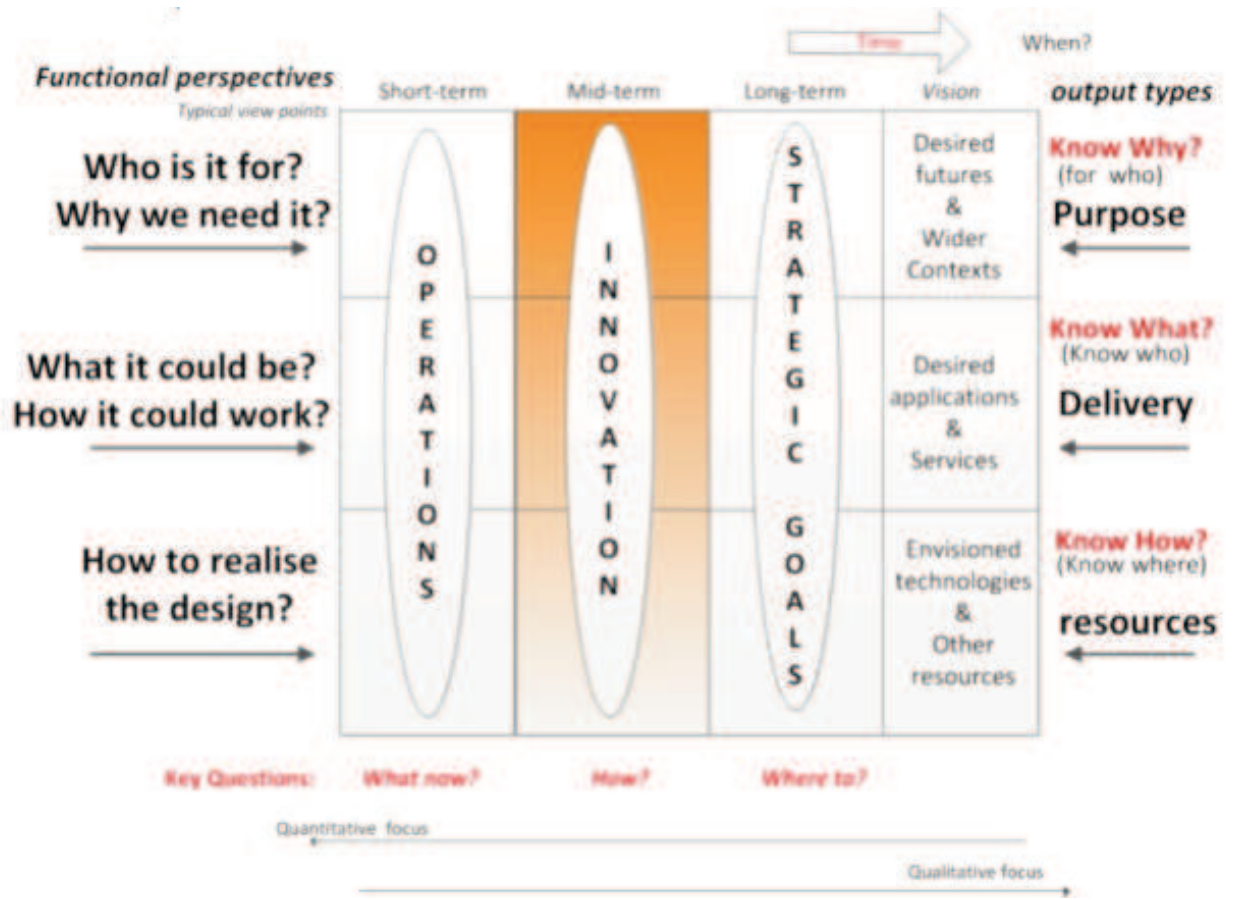

Figure 1: Roadmapping critical framework Source: Kamtsiou (2014) 


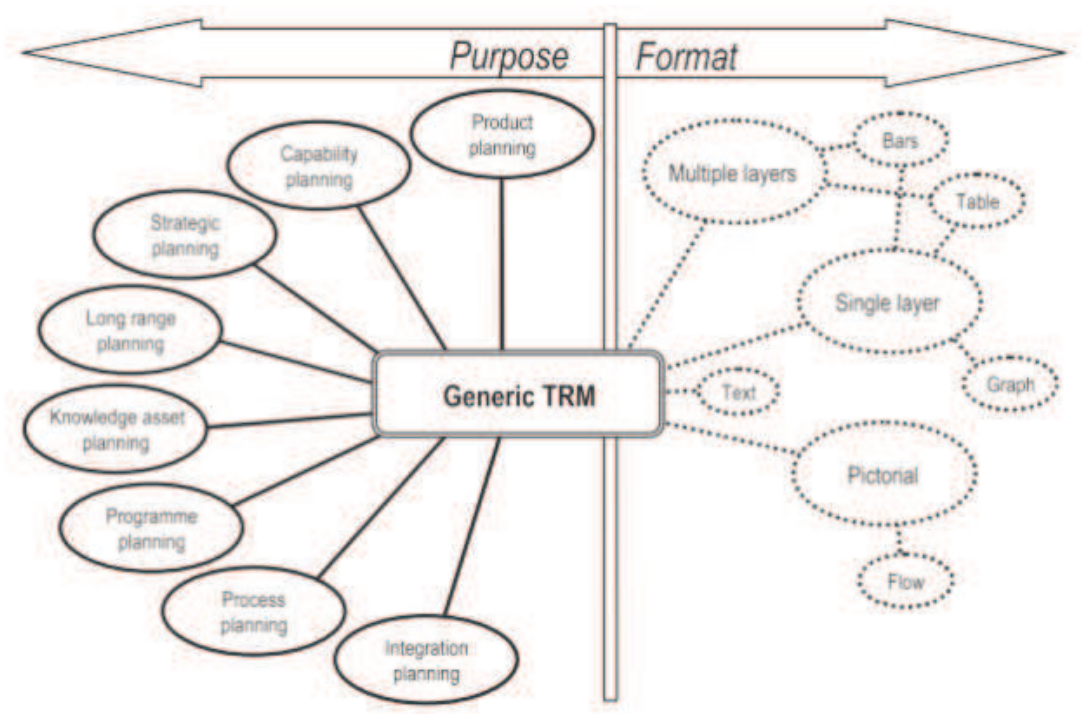

Figure 2: Characterisation of roadmaps Source: Phaal et al. (2004)

action planning (Saritas and Aylen, 2010). According to the various literature reviewed, roadmaps are regarded as aiding decision-making and are useful for: (i) portraying structural relationships among science, technology and applications; (ii) improving coordination of activities and resources in increasingly complex and uncertain environments; (iii) identifying, evaluating, and selecting strategic alternatives that can be used to achieve desired science and technology objectives; (iv) communicating visions to attract resources; (vi) stimulating investigations; and (vi) monitoring progress (e.g. Phaal and Muller, 2009; Amer and Daim, 2010; Saritas and Aylen, 2010). Thus, roadmaps are normative and goal-oriented methods that attempt to achieve a desired future state of development (Saritas and Aylen, 2010).

Traditional technology roadmaps are developed by a company or organisation for the benefit of that same company or organisation; thus, these have been characterised as: a single organisation as the author of the roadmaps; the target audience is the same organisation; and the purpose is mainly to serve as a strategic planning tool (Jeffrey et al., 2013). Nevertheless, roadmaps have evolved to become what Jeffrey et al., (2013) refer to as 'multiorganisation' roadmapping. This entails the application by different types of organisations, for different audiences, and different purposes (Phaal et al., 2004; Jeffrey et al., 2013). They are now utilised at firm, sector and national levels (Phaal and Muller, 2009). Examples of these applications include: process planning, long-range planning, as well as integrated planning (Jeffrey et al., 2013). Of particular interest for this paper is the fact that roadmaps have become popular for integrated energy planning and renewable energy development (Amer and Daim, 2010; Jeffrey et al., 2013). With the evolution of roadmaps, some studies categorise them as first generation roadmaps (1970's to mid1980's); second generation roadmaps (mid 1980s to the end 1990s); and third generation roadmaps (1990 to today) (Kamtsiou, 2014).

Phaal and Muller (2009) point out that the technology roadmap (TRM) is a dynamic or systems framework that provides a coherent and holistic structure, which can be mapped, and thus providing easy communication (see Figure 3). Roadmaps are, however, not limited to the format represented in Figure 3. Typical formats include: multiple layers; bars; network diagrams; and flow charts. Other formats also include: graphs, tables, pictorial presentations, and texts (Saritas and Aylen, 2010). The type of format chosen depends on the purpose of the roadmapping as shown in Figure 2. However, text formats have been used relatively less than the visual formats, which are much easier to communicate and understand. The number of layers that can be utilised in a roadmapping is customised based on the type of roadmap (firm, industry, sector, technology, and so forth) and the type of innovation (Kamtsiou, 2014).

Generally, the typical format representation of the roadmaps allows for the exploration of the development and evolution of the business or system (Phaal and Muller, 2009). This, however, is only true to some extent, as some authors have criticised the roadmap as being more normative than exploratory, encouraging linear and isolated thinking, and lacking focus and clear boundaries (Saritas and Aylen, 2010; Carvalho et al., 2013). Roadmaps mostly address 'what should be' and 'what could be' from the perspective of the participants creating the roadmap; hence, it may not be objective (Kamtsiou, 2014).

As illustrated in Figure 3, the architecture of a roadmap consists of two main dimensions, namely: (i) time, on the horizontal axis; and (ii) layers and 


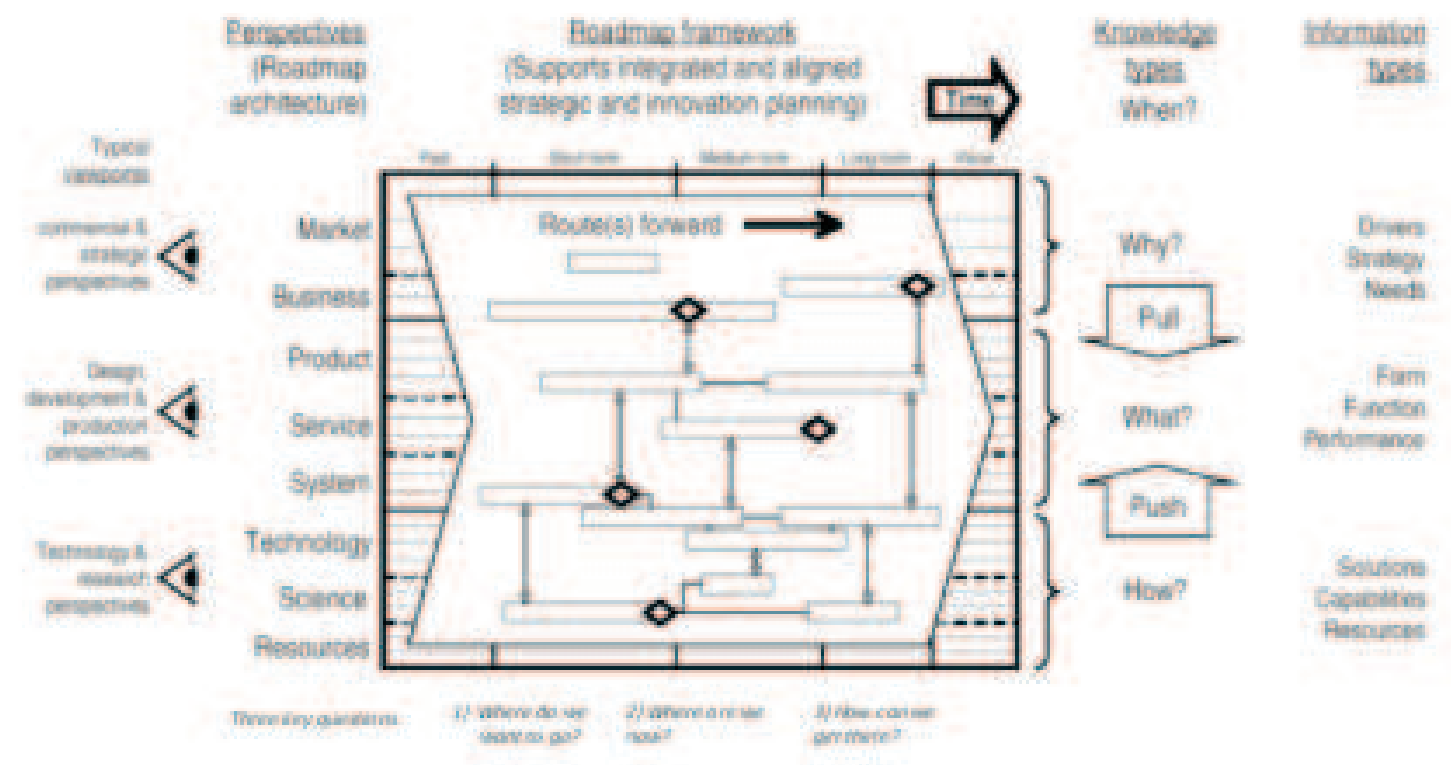

Figure 3: Schematic multi-layered roadmap Source: Phaal and Muller (2009)

sub-layers, which is on the vertical axis. While the linkages between different elements can be represented in the roadmap, the fundamental causal relationships are not depicted (Phaal and Muller, 2009). The typical timeframe for a roadmap is 1 year for short-term; 5 years for medium-term; and 10 years for long-term (Phaal and Muller, 2009). Nevertheless, some studies have considered a longer time frame that is more than 10 years; for instance, Li et al. (2014) and Zhang et al. (2013) and the International Energy Agency (http://www.iea.org/roadmaps/) have taken a longer view of 20 to 50 years, but there are then (obviously) a number of uncertainties involved in the roadmapping process.

The roadmapping process consists of a number of phases. Several studies that have been reviewed seem to agree on three phases, namely: (i) the preliminary activity - which is mainly a scoping stage and includes activities such as information collection for roadmapping, ensuring stakeholders and experts participation, and defining the scope and boundary of the roadmap; (ii) the development of the roadmap - which focuses on what is to be included and excluded in the roadmap, identifying measurable capability levels, and identifying gaps in market, technology and products; and (ii) the follow-up activity - where the roadmapping report is produced for the intended purpose (Saritas and Aylen, 2010; Cavallaro and Ciraolo, 2005; Phaal et al., 2004; Phaal and Muller, 2009). All these roadmapping phases can generally be considered to follow the phased approach of Phaal and Muller (2009); illustrated in Figure 4. That is, each phase consists of a process of 'ideation, divergence, convergence and synthesis'.

It was observed in the literature that there is no single method that can be utilised when developing a roadmap. Generally, the methods, approaches and tools utilised are based upon the three key questions of the roadmapping process that were highlighted in Table 1, viz: (i) 'where do we want to go?'; 'what are the ways of getting there?'; and 'what should be done from now on?' (Saritas and

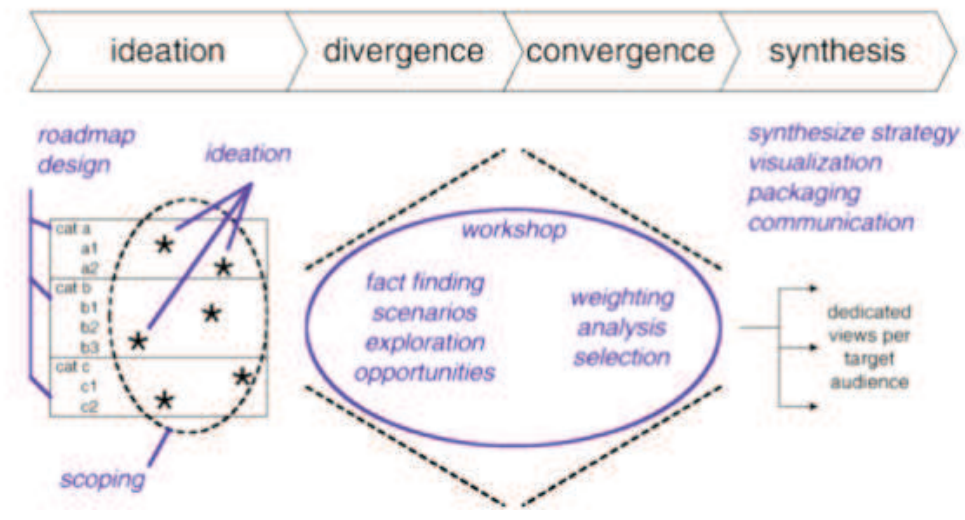

Figure 4: Phased approach of roadmapping process Source: Phaal and Muller (2009) 
Aylen, 2010; Carvalho et al., 2013). Thus, different methods can be used depending on the phase of the roadmapping process and the objectives of a roadmap. The next section hence discusses the approaches and methods that can be utilised to develop roadmaps.

\subsection{Methods and approaches to develop roadmaps}

According to De Piante Henriksen (1997) and Tran (2007) roadmapping is one of the tools and methods for technology assessment; that is used for forecasting. However, in the process of developing a roadmap, it is utilised hand-in-hand with other technology assessment methods such as economic analysis tools (e.g. cost benefit analysis); decision analysis tools (e.g. Delphi); systems tools (e.g. systems optimization); market analysis methods (e.g. scenario analysis); and externalities and impact analysis methods. On one hand, this is an advantage to the roadmapping as it can allow one to combine different methods and tools. It is predominantly future oriented and uses methods that are common in future studies, for instance: Delphi, crossimpact analysis, weak signal, as well as methods for providing an understanding in strategic visioning, e.g. conceptual modelling, discourse management, and scenario planning (Kamtsiou, 2014). On the other hand, given the diversity of methods and tools that can be utilised, there are generally no standardised methods and approaches to technology roadmapping. Hence, the selection of the specific methods used in some studies seems to be (somehow) subjective.

On a different note, studies have been identifying ways of improving the limitations of roadmapping. The main limitations identified in the literature include: the roadmaps are difficult to disseminate; are generally normative rather than exploratory; are difficult to use to evaluate the value of business; are difficult to express attractiveness of the outputs of research and development; are difficult to express operational models; are difficult to customize; they encourage linear and isolated thinking; provide little guidance; lack focus and clear boundaries; and lack reliability and objectivity (Carvalho et al., 2013). In the recent past, emerging studies have identified the need for transforming roadmapping such that it is more flexible, dynamic and operationalizable. For instance, Gerdsri and Kocaoglu (2007) developed the concept of a technology development envelope (TDE) in order to "keep the roadmap alive'. The purpose of the TDE is to link the development of technologies within the framework of the organisation's strategy, as well as the expected future development of the technologies. The concept emphasises the use of both the Delphi method, to obtain strategic information on technological future development, and the analytical hier- archy process, to evaluate the impact of the technologies against the organisation's objective(s).

While Gerdsri and Kocaoglu (2007) argue that the TDE introduces a flexible, dynamic and operational feature, this paper argues that the dynamics is only introduced to a limited extent and feedback loops of the different elements are not taken into account. Further, the focus in the use of an analytical hierarchy process only allows in determining the optimal path, rather than a set of potential plausible paths. As a result, limited scenario planning can be undertaken with the TDE.

Robinson and Propp (2008) introduced the concept of 'multi-path mapping', which is basically aimed at forecasting the likely future development of new technologies based on emergence dynamics. Other studies have introduced scenario planning as part of improving the technology roadmap. For instance, Postma and Liebl (2005) highlight ways of improving conventional scenario methods by using recombinant scenarios, context scenarios, or inconsistent scenarios, or combination of these.

While roadmaps are presented in a time-based format showing the multi-layers that link the technology-related issues needed for strategic decisionmaking (Gerdsri and Kocaoglu, 2007), the system dynamics approach is rarely utilised to capture the causal interrelationships between the different elements involved (e.g. markets, products, technology, and others) over time. Hence, despite the efforts of improving scenario planning, the challenge is that most of these efforts have been conceptual with limited levels of operationalization. From the literature analysis, the study of Geum et al. (2014) is the first study that has integrated technology roadmap and system dynamics in order to support scenario planning. They argue that dealing with the uncertainties involved in the roadmapping process, system dynamics becomes necessary for mapping potential plausible pathways.

The challenge found with the many roadmapping studies done is the lack of the indication of the specific methods utilised throughout the roadmapping process. In cases where the method was indicated, there was a lack of clarity on the phase at which the method was utilised in the roadmapping process. Nevertheless, Saritas and Aylen (2010) provide a framework in which roadmapping can be combined with other technology assessment methods. As observed in Figure 5, they grouped these into methods that can enable: (i) understanding; (ii) synthesis and models; (iii) analysis and selection; (iv) transformation; and (v) action. This classification provides a useful way of informing methods, tools and approaches to use for future roadmapping.

Given the different methods identified, one may question as to what would be the appropriate way of selecting methods in the development of a 


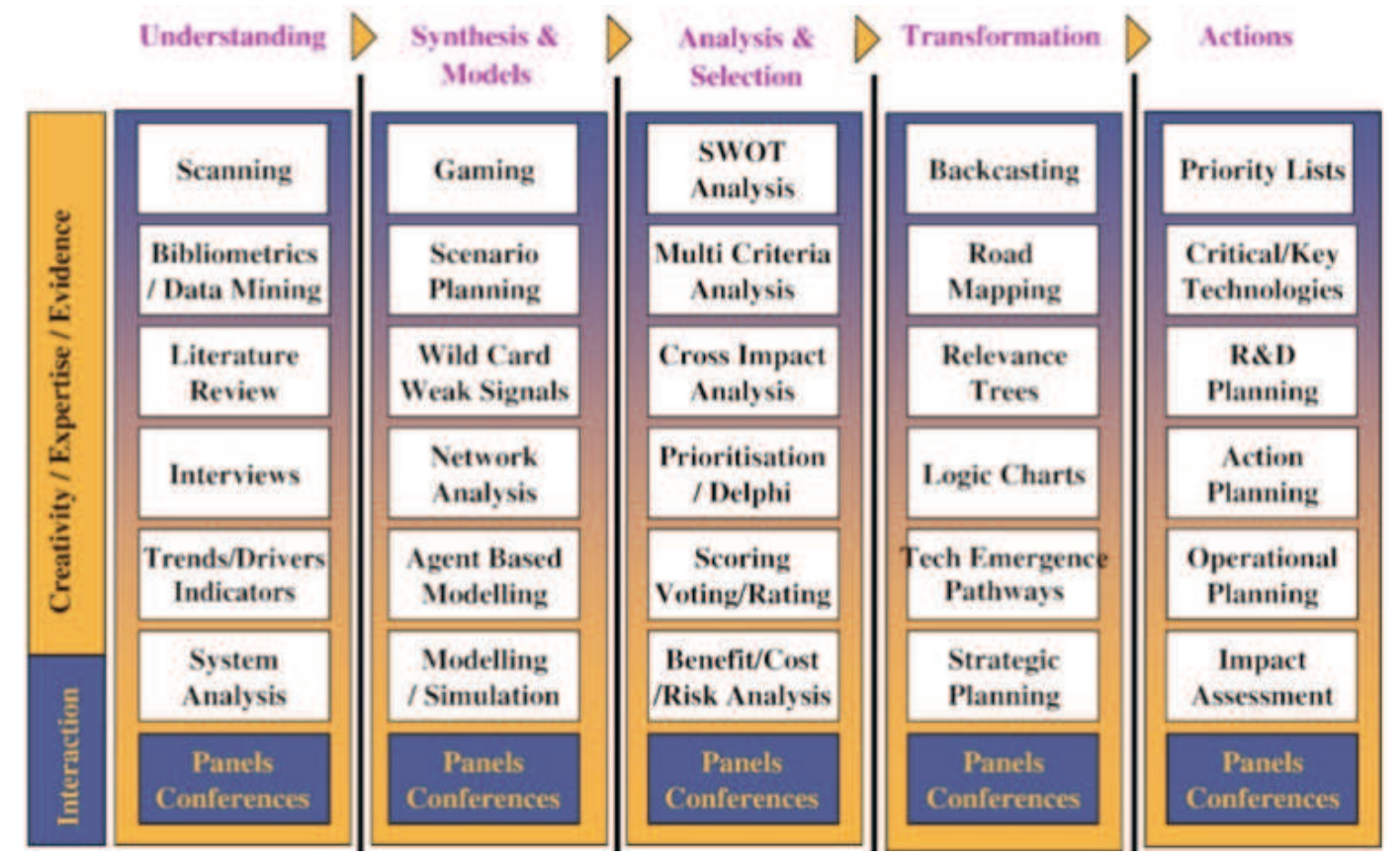

Figure 5: The place and function of scenarios and roadmapping in Foresight methodology Source: Saritas and Aylen (2010)

roadmap. According to Kamtsiou (2014), the type of roadmap developed is basically what informs the methods that could potentially be utilised. They thus classified the type of methods utilised based on the type of roadmap, as shown in Figure 6. The method, which is of particular relevance to this paper, is the strengths, weaknesses, opportunities and threats (SWOT) analysis, which entails a situation analysis for explaining the internal (strengths, weaknesses) and external (opportunities, threats) factors of any strategy (Pesonen and Horn, 2014), undertaken for technology development.

The type of roadmap considered in this paper could be categorised as exploratory in that it integrates an emerging technology within the context of South African energy planning. Given that the specific context for roadmapping in this paper is solar energy, the next section discusses the extent to which roadmaps have been utilised in the renewable energy sector.

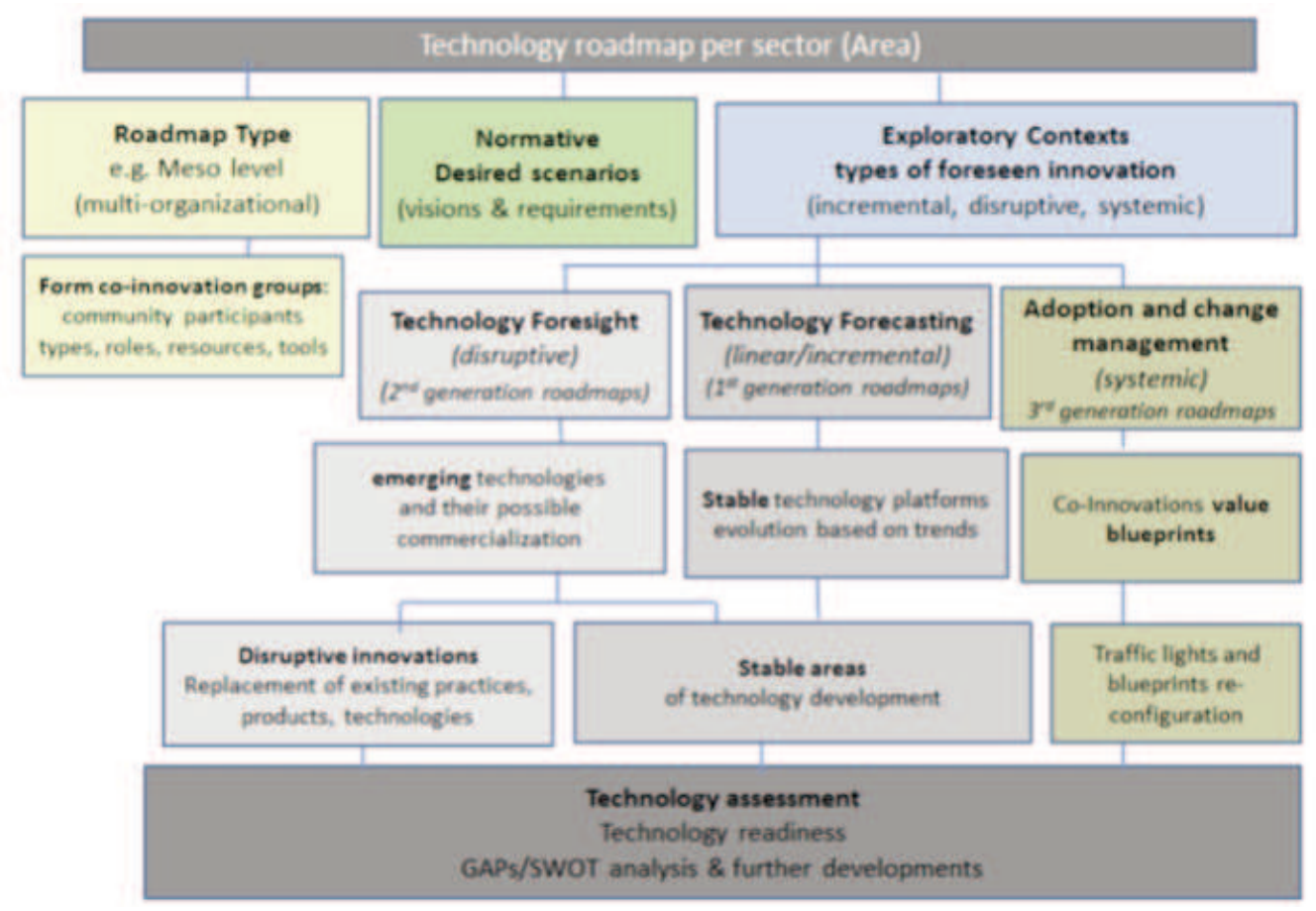

Figure 6: Classification of methods by technology roadmap type Source: Kamtsiou (2014) 


\subsection{Roadmaps in the renewable energy sector}

Amer and Daim (2010) undertook a literature review to establish the extent to which roadmapping has been applied in the renewable energy sector. In their review, they found that the use of roadmaps in the renewable energy sector has been extensive, and in particular, it has been used to: (i) create and develop a common vision; (ii) establish long-term goals; (iii) assess alternative technologies that seem promising; (iv) provide guidelines for policy- and decision-makers; (v) inform the potential future development of the energy sector; (vi) prioritise research and development projects; and (vii) develop a framework for public-private collaborations for technologies identified in the roadmapping process. Despite the wide application of roadmaps in the renewable energy, the question is whether the objectives of the roadmapping process are being translated into actions.

Jeffrey et al. (2013) identified the success of roadmaps in the renewable energy sector. They found that the way in which the success for the roadmaps can be measured has been evolving as well, and are currently different from the traditional roadmaps. Given that roadmaps in renewable energy involve multiple stakeholders and organisations, their objective has mainly been to persuade governments and other stakeholders to implement the recommendations that are set out from the roadmapping process. For instance, the International Energy Agency has developed energy roadmaps for the different technologies at a global scale. Country-specific technology roadmaps have also been developed for wind (e.g. Daim et al., 2009); photovoltaic (e.g. Hutchby, 2014); solar cell technology based industry (e.g. Li et al., 2014); and hydrogen energy (e.g. McDowall, 2012), among others. Other studies have undertaken comparative technology roadmaps for renewable energy (e.g. Cowan and Daim, 2009). However, solar aided power generation is a recent concept and it seems no roadmap has been developed for the technology as yet.

In the development of the roadmap in this paper, it would thus be essential to utilise multiple approaches, methods and tools. The next section discusses the general guidelines for developing a renewable energy roadmap.

\subsection{Guidelines to developing a renewable energy roadmap}

According to the literature, the development of a roadmap usually begins with the identification of stakeholder(s) and bringing them into a workshop (Amer and Daim, 2010). Given the growing governments' interest in using roadmaps in energy planning, the International Energy Agency (2010) provides guidelines to the development and implementation of a roadmap.

According to the guidelines, on average, it takes six to fourteen months to develop a roadmap (see Figure 7). In addition, two processes that are mainly involved are: (i) expert judgment and consensus; and (ii) data and analysis, which occur throughout the four phases highlighted in Figure 7, that is: planning and preparation; visioning; roadmap development; and roadmap implementation and revision.

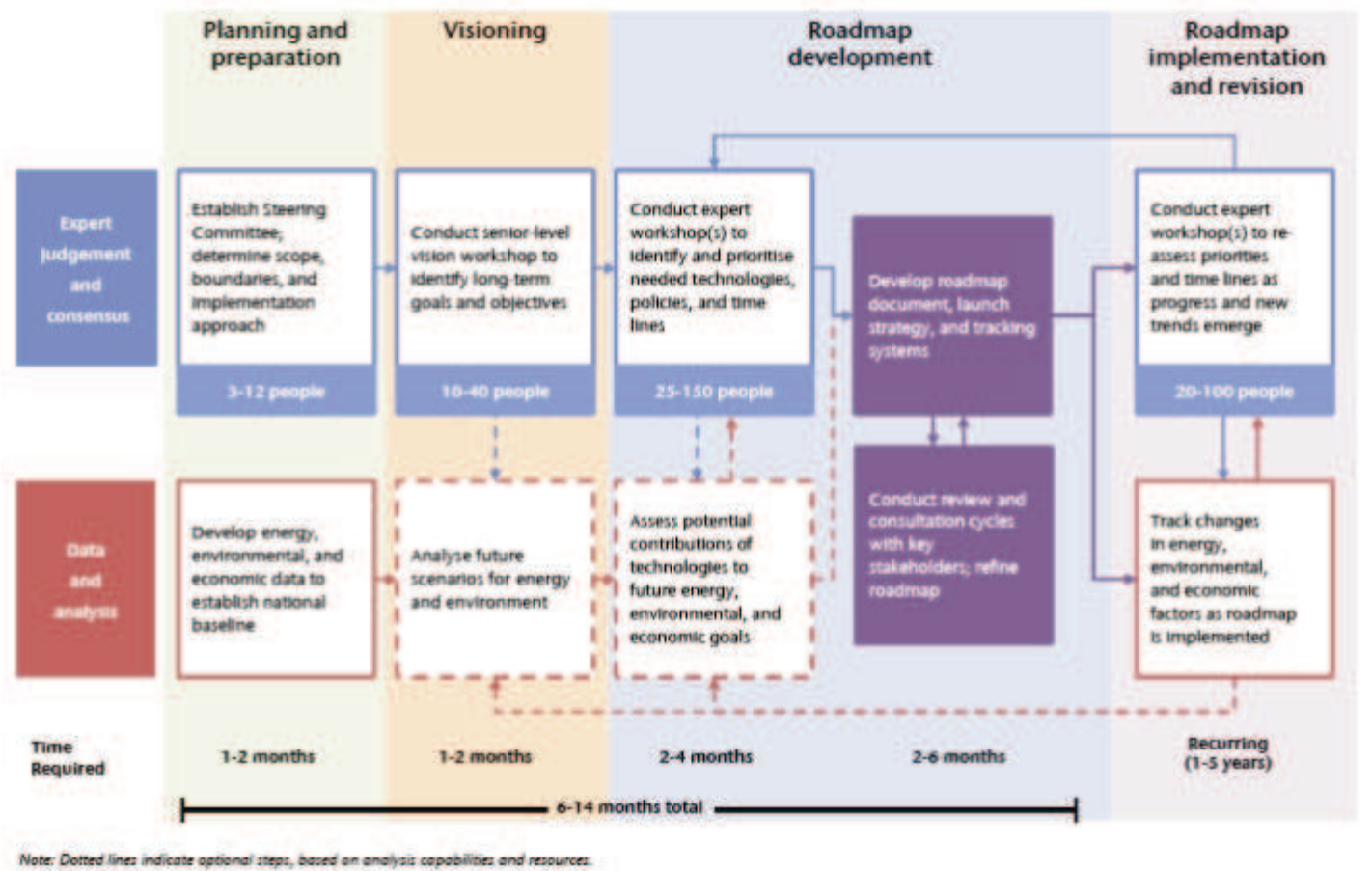

Figure 7: An outline of roadmap process

Source: International Energy Agency (2010) 
The expert judgement and consensus can be seen as similar to the phased approach of Phaal and Muller (2009) as shown in Figure 4, involving processes of 'ideation, divergence, convergence and synthesis'.

The aim of this paper was not to go through the entire roadmapping process, but to provide sound data and analysis to establish: (i) current baseline for solar aided power generation technology including market drivers, environmental issues, government policy and business opportunities; (ii) milestone and performance targets; and (iii) pathways to achieve roadmap goals. All these were aimed to better inform the planning and preparation, visioning and roadmap development for solar aided power generation.

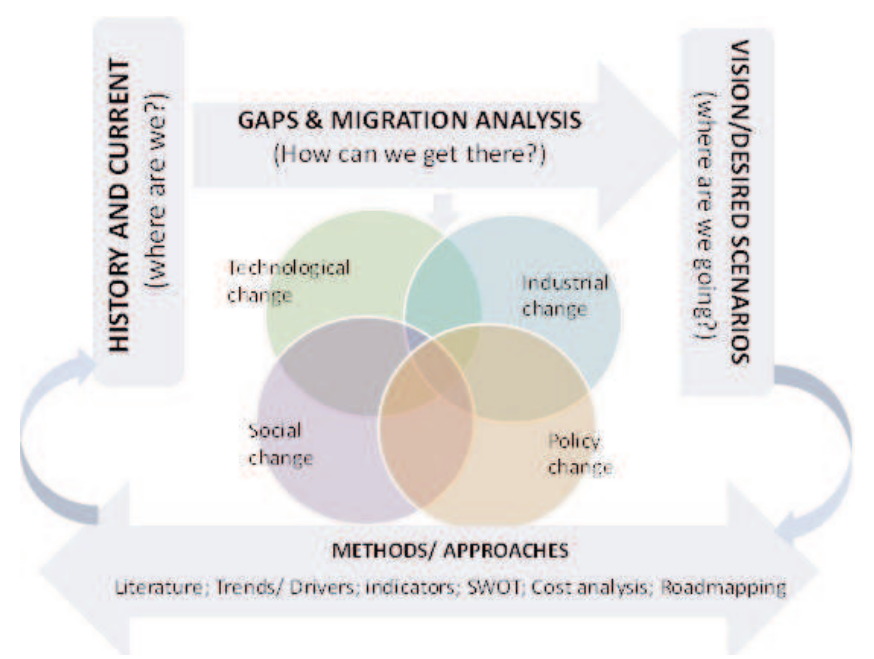

Figure 8: Conceptual framework

Source: Developed by the authors based on roadmapping literature

\section{Conceptual method/framework}

In this section, a conceptual basis for the renewable energy technology development roadmap is provided. The framework serves as a coherent structure for the practical application of the solar aided power generation technology.

\subsection{The conceptual framework}

The conceptual framework developed for this paper (Figure 8 ) is based on the roadmapping literature analysis. The key references that informed the development of the framework are: (i) Phaal et al. (2004) with regards to the phases in technology roadmapping; (ii) Saritas and Aylen (2010) with regards to methods that can be utilised in the data and analysis phase; (iii) Konnola (2007) with regards to systems of innovation theory, in order to inform migration analysis; and (iv) Huang et al. (2014) in informing the context of gap and migration analysis, which should entail a national context for target technology, the market and industry of the target technology, and impacts of the technology.

a) History and current understanding of renewable energy technology

This involves establishing the history and present status of the technology; the energy policy and regulatory framework; market drivers; organisational and technological requirements; and public perception of the technology. This is aimed at building knowledge of the technology through desktop research and mapping out major actors that would be involved in identified renewable energy technology development. As per Saritas and Aylen (2010), the methods to be utilised are for understanding, and include: literature reviews; trends; and indicators.

\section{b) Gaps and migration paths of the renewable} energy technology

This involves the identification of the gaps of the technology and migration paths towards achieving the vision/ desired goals. The migration paths involve identifying the technological change; social change, industry change, and policy change, which represent the dimensions of systems innovation (see Table 2). This activity was aimed at providing the information on the feasibility in achieving the desired goals; hence it is a forward-looking activity. Methods that were identified for use in this paper were trends and indicators, and a SWOT analysis.

\section{c) Vision / desired scenarios of the renewable} energy technology

This involves establishing the desired visions and scenarios for the case study technology. This was based on establishing what already exists, either in

Table 2: Description of systems innovation dimensions

Source: Konnola (2007)

\begin{tabular}{ll}
\hline Dimensions of systems innovation & \multicolumn{1}{c}{ Core concepts and elements } \\
\hline Technological change & Dominant designs, emerging technologies, infrastructures, interoperability. \\
\hline Industrial change & $\begin{array}{l}\text { Standards, value chain and networks, organisational hierarchies and practices, } \\
\text { investment mechanisms, intellectual property. }\end{array}$ \\
\hline Policy change & $\begin{array}{l}\text { Information services, networking, setting common agendas, strategic procurement, } \\
\text { financing research and education, grants, equity support and fiscal measures, } \\
\text { regulation and standards. }\end{array}$ \\
\hline Social Change & Behaviour, routines, preferences, attitudes, values, user involvement. \\
\hline
\end{tabular}


the policy documentations, or in strategies and plans.

d) Methods and approaches selected for the case study

As mentioned earlier, the conceptual framework in this paper mainly focussed on the methods and approaches that would be utilised in informing the data and analysis activities of the roadmapping process for the selected case study - solar aided power generation. As such, it was not within the scope of this paper to utilise methods that would require engagement with other stakeholders; for example, by utilising the Delphi method. In addition, given the timeframe for the roadmapping process (refer to Figure 7), the paper was limited as to how it could utilise scenario planning and modelling. Thus, the methods that were identified and utilised in this paper were: a literature review; trends / drivers indicators; cost analysis; and a SWOT analysis.

4. Case study: solar aided power generation This section utilises the conceptual framework to describe the case of solar aided power generation. The roadmap developed in this paper can be considered as an integration planning one, as it mainly focusses on integrating a technology within the current framework (refer to Figure 2).

\subsection{Current state of electricity generation in South Africa}

Electricity generation from coal is and will still continue to be the main backbone of the South Africa economy, despite that it hugely contributes to $\mathrm{CO}_{2}$ emissions. Coal electricity generation in South Africa contribute about $90 \%$ of the total electricity supply (Department of Energy, 2010). The rest is supplied from nuclear $(4.2 \%)$, hydro $(2.4 \%)$ and the remainder from renewables. Coal-generated electricity, however, contributes to about $60 \%$ of $\mathrm{CO}_{2}$ emissions in the country (Blignaut et al.,
2005). In order to deal with this environmental challenge, South Africa has put a plan to diversify its electricity generation by increasing renewable energy capacity. In 2012, South Africa was the fourth largest in the world in terms of the share of GDP invested in renewable energy (REN21, 2014).

One option that has been considered is building stand-alone renewable energy plants. However, this option is not currently cost competitive, especially for large-scale utility renewable electricity generation. The second option, which is the case considered in this paper, is the integration of renewable energy with the fossil fuel technology; that is, to integrate solar (thermal) energy and coal power generation. Concentrating solar thermal power has a high potential for utility-scale electricity generation. However, it is not yet cost effective and hence less attractive. An alternative to dealing with the current situation is to modify existing coal power stations to generate more power efficiently by integrating solar thermal technologies, which is commonly known as solar aided power generation. A detailed explanation of the technology is discussed in Section 4.2 .

Given the above brief overview, Table 4 presents a SWOT analysis of the current state of the electricity generation at utility scale in South Africa.

\subsection{The technology: solar aided power generation}

The solar aided power generation concept has been developed in order to combine the strengths of two technologies, namely: the traditional regenerative Rankine cycle, which has relatively higher efficien$\mathrm{cy}$, and solar heating at relatively low temperature range (Pierce et al., 2013; Hu et al., 2010). Apart from increasing the efficiencies of the conventional power station and reducing $\mathrm{CO}_{2}$ emission, solar aided power generation also provides a better way of utilising solar heat to generate the power. Solar aided power generation would thus contribute to the diversification of electricity generation while

Table 3: SWOT analysis of the current state of utility scale electricity generation

\begin{tabular}{|c|c|}
\hline Strengths & Weaknesses \\
\hline Abundant coal for electricity generation & Low contribution of electricity generation from renewables \\
\hline Alternative renewable resources especially solar & $\begin{array}{l}\text { Lack of consideration of RE-fossil fuel hybrid technologies in } \\
\text { current IRP }\end{array}$ \\
\hline $\begin{array}{l}\text { Existing programme for renewable energy } \\
\text { procurement }\end{array}$ & Constrained electricity generation due to increasing demand \\
\hline Threats & Opportunities \\
\hline Dependency on coal generated electricity & Use of solar aided technologies \\
\hline Social conflict & Public-private partnership options \\
\hline Climate change & Incorporation in REIPPPP \\
\hline Financial crisis & Green jobs \\
\hline
\end{tabular}


ensuring that the cost of electricity generation is affordable, and energy supply security is ensured (Hu et al., 2010; Pierce et al., 2013).

In the South African context, Pierce et al. (2013) have found solar preheating of feedwater as a more feasible solution in the short- to medium-term, in combination with the coal base. The basis for the solar aided power generation is replacing the bledoff steam in the regenerative Rankine power cycle with solar thermal (regarded as 'solar boosting mode'), or reducing fuel consumption (regarded as 'fuel saver mode') ( Pierce et al., 2013).

\subsection{Market and industry for solar thermal collectors}

Globally, the market for solar thermal power continued to grow in 2013 after record growth in 2012. According to REN21 (2014), the total global capacity increased by nearly $0.9 \mathrm{GW}$, up $36 \%$, to more than $3.4 \mathrm{GW}$ as shown in Figure 9.

There are different concentrating solar thermal collectors, namely: parabolic trough, linear Fresnel, concentrating power tower, and the dish Stirling. The characteristics of the solar thermal collectors, the capital costs, and typical energy costs are shown in Table 5. As observed, the typical energy cost is not competitive. These costs are comparable to recent costs of solar thermal collectors in South Africa. For instance, based on the Renewable Energy Independent Power Producers Procurement Programme (REIPPPP) Bid window 3, the cost of fully indexed average cost of concentrating solar power (CSP) was $1.64 \mathrm{Rand} / \mathrm{kWh}$, while the current cost of coal generation is $0.74 \mathrm{Rand} / \mathrm{kWh}$.

According to REN21 (2014), the focus on concentrating solar thermal power has shifted to the Middle East and North Africa (MENA) region and South Africa. Further, REN21 (2014) indicates that South Africa has remained one of the most active markets, with $100 \mathrm{MW}$ of parabolic trough and 100 MW of power tower capacity under construction; with a further $200 \mathrm{MW}$ in the immediate pipeline. There is thus a potential to increase the capacity of CSP for boosting the coal power plants.

\subsection{Solar thermal energy policy}

As per the revised Integrated Resource Plan (IRP) for electricity, the total CSP allocation is $1000 \mathrm{MW}$ from 2016 to 2025, while that of coal is $6250 \mathrm{MW}$ from 2014 to 2030 (see Figure 10). There is no policy that provides for combining the two technologies - solar aided power generation - nor does the

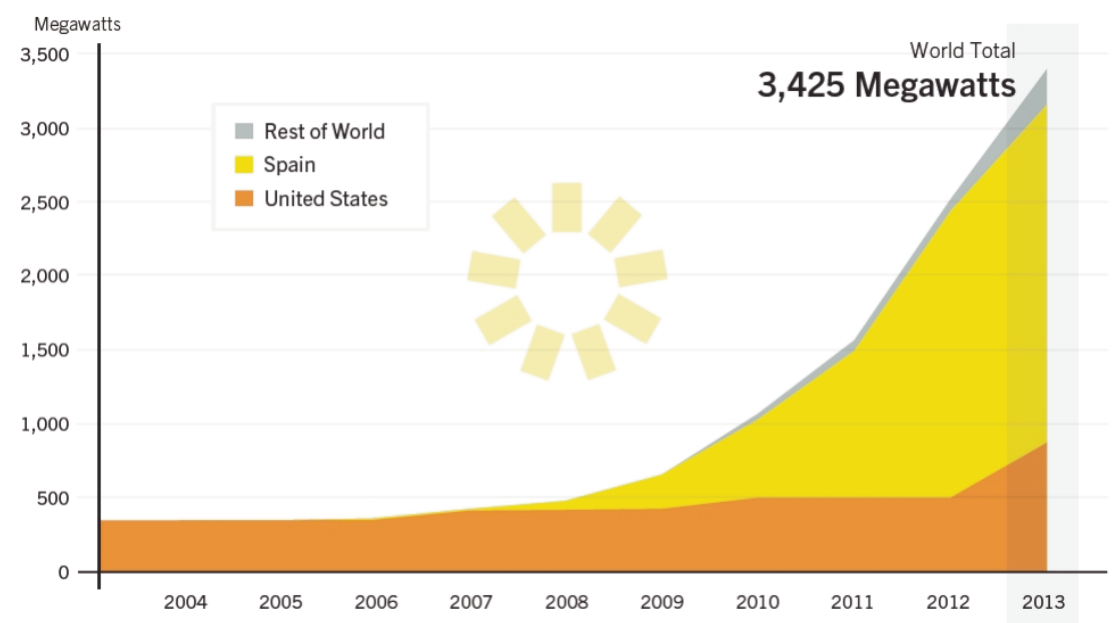

Figure 9: Concentrating solar thermal power, global capacity Source: REN21 (2014)

Table 4: Characteristics of solar thermal collectors Source: REN21 (2014)

\begin{tabular}{lll}
\hline $\begin{array}{l}\text { Characteristic of the solar thermal collectors technology } \\
\text { Typical energy costs }\end{array}$ & Capital costs (USD/kW) \\
\hline LCOE - U.S. cents / kWh & & \\
\hline Types: parabolic trough, tower, & Trough, no storage: & Trough and Fresnel: \\
dish Plant size: & $4,000-7,300$ (OECD); & $19-38$ (no storage); \\
50-250 MW (trough); & $3,100-4,050$ (non-OECD) & $17-37$ (6 hours storage) \\
20-250 MW (tower); & Trough, 6 hours storage: & Tower: \\
10-100 MW (Fresnel) & $7,100-9,800$ & $12.5-16.4$ (United States; high end \\
Capacity factor: & Tower: 5,600 (United States, & of range is with storage) \\
20-40\% (no storage); & without storage) 9,000 (United & \\
$35-75 \%$ (with storage) & States, with storage) & \\
\hline
\end{tabular}




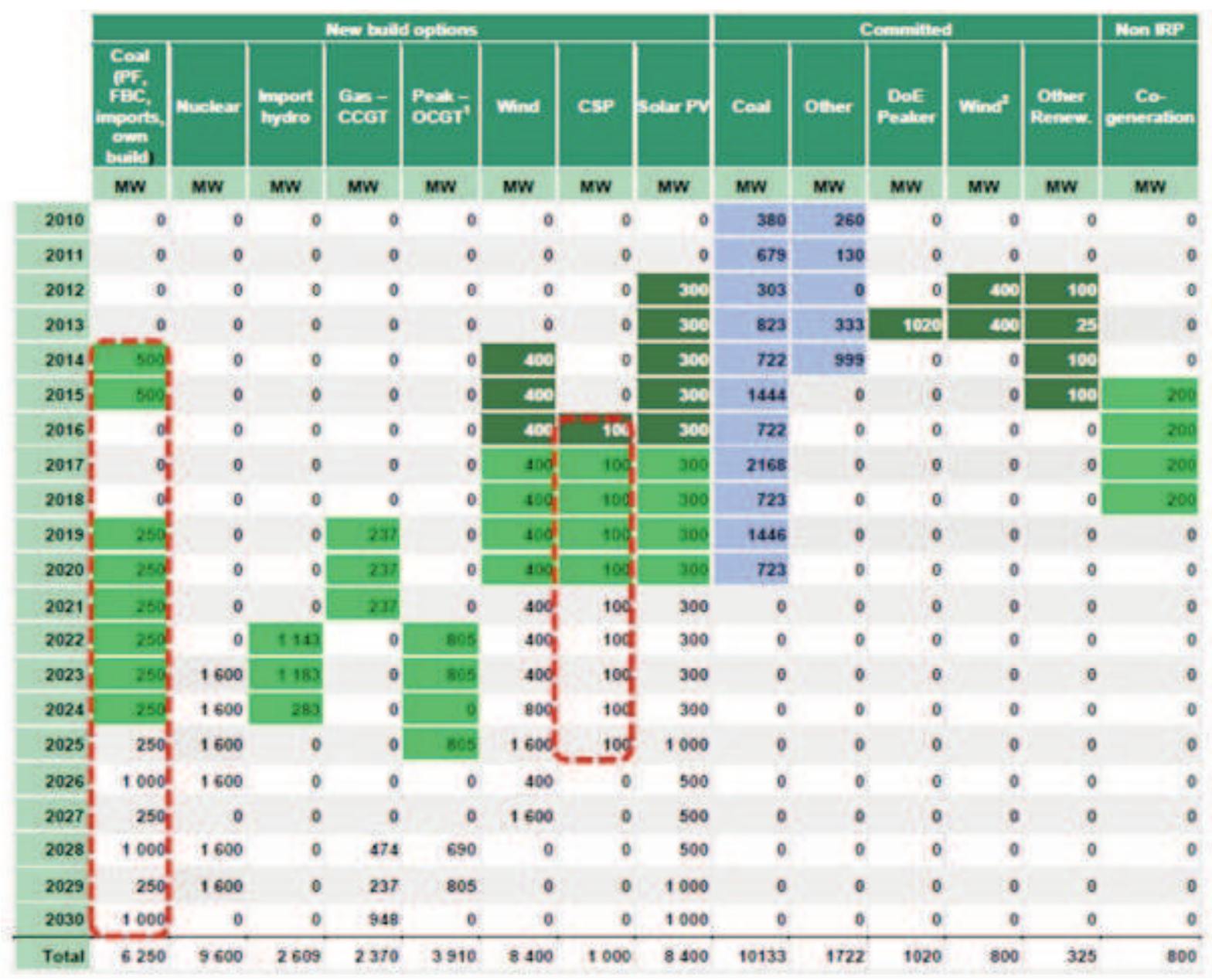

Figure 10: IRP2010 Policy adjusted plan

Source: Department of Energy (2013)

solar aided power generation feature in the REIPPPP. Despite this challenge, opportunities are available for introducing the solar aided power generation within the IRP framework or within the existing public-private partnership (PPP) of the National Treasury.

\subsection{Drivers for solar aided power generation}

The main drivers for solar aided power generation is the need to combine the benefits of the solar thermal technology and coal power plants in order to produce cost effective electricity, reduce the environmental impacts, mainly $\mathrm{CO}_{2}$ emissions, and improving generation efficiency. Currently, solar thermal is not cost effective for utilisation as base load, given that the storage technology is costly. A recent study by Pierce et al. (2013) attempted to provide estimates of the cost of solar aided power generation in South Africa in comparison with a stand-alone concentrating solar power (CSP). They found that the cost of solar aided power generation (SAPG) is $72 \%$ of the cost of a stand-alone CSP. Further, they found that solar aided power generation generates in excess of $25 \%$ more electricity than stand-alone CSP and is 1.8 times more cost effective than the stand-alone CSP option (Pierce et al., 2013). Given the limited quantitative data for undertaking a cost benefit analysis, Table 6 presents the (potential) benefits and disadvantages of solar aided power generation.

Despite the potential benefits of the technology, most countries are hesitant to adopt it, with the exception of Australia, China, USA and India (Pierce et al., 2013). In South Africa, Eskom, the national electricity utility, is investigating the feasibility of utilising the technology (Pierce et al., 2013).

\subsection{Solar aided power generation stakeholder analysis}

After analysing the current status with respect to the energy sector, a stakeholder analysis was carried out as shown in Figure 11. This was done to identify each stakeholder's position with respect to 'interest' in developing a sustainable energy policy, and the extent to which they have 'power' to influence decision-making processes. This analysis provides a practical tool to identify how to approach and motivate each stakeholder to achieve the proposed goal of integrating solar aided power generation in the current policy frameworks.

Some potential coalitions were identified, namely: 
Table 5: Advantages and disadvantages of solar aided power generation Source: Compiled based on various literature sources including Hu et al. (2010); Bakos and Tsechelidou (2013); and Pierce et al. (2013)

\begin{tabular}{ll}
\hline \multicolumn{1}{c}{ Advantages } & \multicolumn{1}{c}{ Disadvantages } \\
\hline $\begin{array}{l}\text { Increasing the electricity efficiency } \\
\text { Reduction in generation cost }\end{array}$ & $\begin{array}{l}\text { Potential competition with CSP IPP's } \\
\text { Not getting away from coal still emitting higher } \mathrm{CO}_{2} \\
\text { than stand-alone solar thermal }\end{array}$ \\
$\begin{array}{l}\text { Higher exergy efficiencies } \\
\text { Utilising existing infrastructure (and existing grid) }\end{array}$ & $\begin{array}{l}\text { Potential coalitions } \\
\text { Can be applied to modify existing plants } \\
\text { Thermal storage is still technically immature and not } \\
\text { required in this case }\end{array}$ \\
$\begin{array}{l}\text { Flexible to implement } \\
\text { Increase energy security } \\
\text { Improve affordability electricity } \\
\text { More jobs created than stand-alone solar thermal }\end{array}$ \\
\hline
\end{tabular}

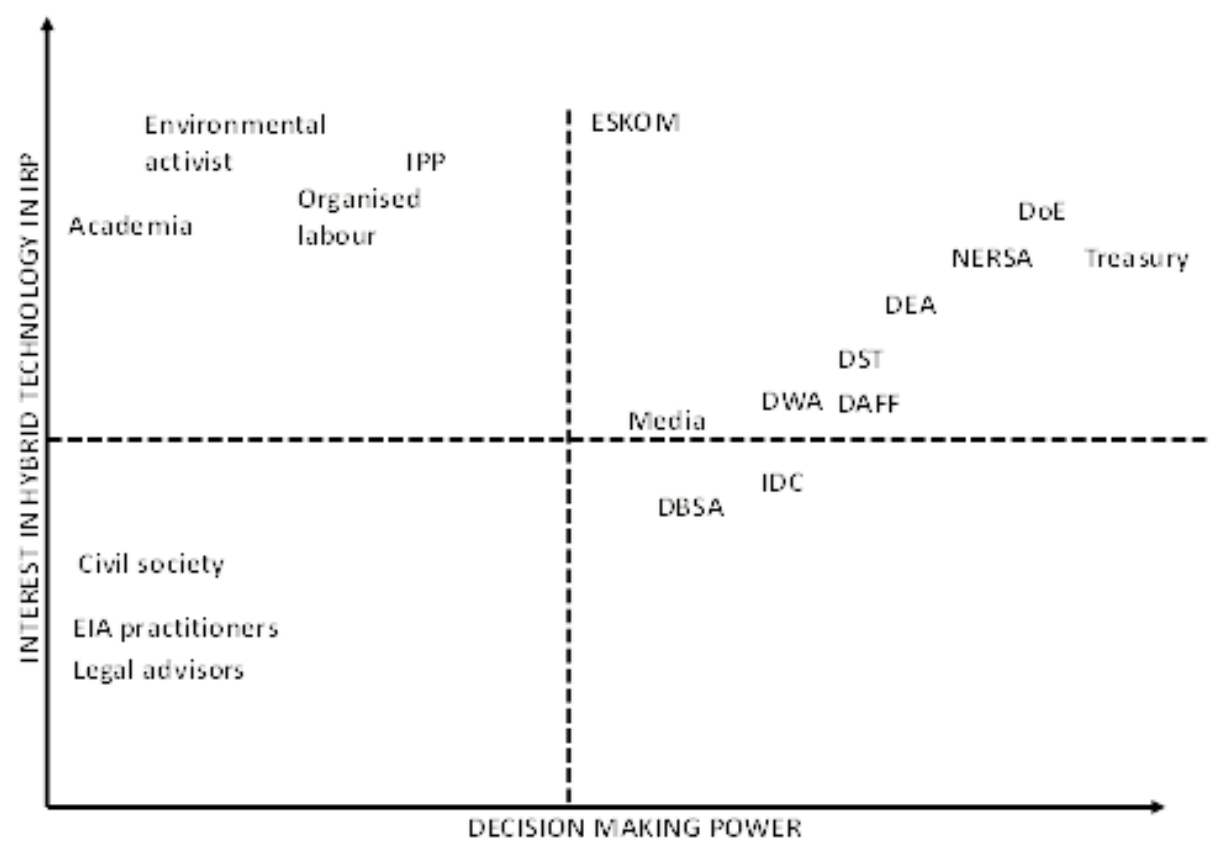

The full names of abbreviated stakeholders are as follows: IPP - Independent Power Producer; DoE - Department of Energy; NERSA - National Energy Regulator South Africa; DEA - Department of Environmental Affairs; DST - Department of Science and Technology; DWA - Department of Water Affairs: DAFF- Department of Agriculture, Forestry and Fisheries; DBSA -Development Bank Southern Africa; IDC -Industrial Development Corporation; EIA - Environmental Impact Assessment.

\section{Figure 11: Potential stakeholders in solar aided power generation Source: Based on authors' analysis}

(i) Potential stakeholders who would be willing to support the solar aided power generation. These include Eskom, some potential IPPs, and National Treasury, if the public private partnership option is taken into consideration.

(ii) Potential stakeholders who would be against the solar aided power generation as they may consider this as still promoting the fossil fuel electricity generation. These include environmental activists such as Greenpeace, some potential IPPs within the REIPPPP process who may see this as a threat.

(iii) Neutral group, who could either move to the pro and against coalition depending on which of these groups are more persuasive in the sup- port of policy- and decision-making. These include mainly the government departments such as the Department of Energy, the Department of Science and Technology, and the Development Bank of Southern Africa.

\subsection{Solar aided power generation migration analysis}

It should be noted that the support for solar aided power generation is only best suited for the short- to medium-term. This has indeed been indicated by the various studies reviewed (e.g. Hu et al., 2010; Pierce et al., 2013). In the long-term, it will be essential to support stand-alone CSP. The assumption is that CSP technology would be cost-effective 
Table 6: Solar aided power generation migration analysis

\begin{tabular}{|c|c|c|c|c|}
\hline & Present & Short term & Medium term & Long-term \\
\hline Technological change & $\begin{array}{l}\text { Coal power stand } \\
\text { alone and CSP stand } \\
\text { alone }\end{array}$ & $\begin{array}{l}\text { Solar aided power } \\
\text { generation }\end{array}$ & $\begin{array}{l}\text { Solar aided power } \\
\text { generation }\end{array}$ & CSP \\
\hline Industrial change & & $\begin{array}{l}\text { Renewable energy } \\
\text { IPP lobby for solar } \\
\text { aided power } \\
\text { generation }\end{array}$ & $\begin{array}{l}\text { Renewable energy } \\
\text { IPP lobby for solar } \\
\text { aided power } \\
\text { generation }\end{array}$ & $\begin{array}{l}\text { Renewable energy } \\
\text { IPP lobby to } \\
\text { support stand-alone } \\
\text { CSP }\end{array}$ \\
\hline Policy change & $\begin{array}{l}\text { Fossil fuel and CSP } \\
\text { stand alone in IRP }\end{array}$ & $\begin{array}{l}\text { Incorporating solar } \\
\text { aided power gener } \\
\text {-ation in IRP / PPP }\end{array}$ & $\begin{array}{l}\text { Incorporating solar } \\
\text { aided power gener- } \\
\text { ation in IRP / PPP }\end{array}$ & $\begin{array}{l}\text { Support mechan- } \\
\text { isms for stand-alone } \\
\text { CSP }\end{array}$ \\
\hline Social change & $\begin{array}{l}\text { Public support for } \\
\text { renewables }\end{array}$ & $\begin{array}{l}\text { Public support for } \\
\text { solar aided power } \\
\text { generation }\end{array}$ & $\begin{array}{l}\text { Public support for } \\
\text { solar aided power } \\
\text { generation }\end{array}$ & $\begin{array}{l}\text { Acculturation to } \\
\text { solar aided power } \\
\text { generation to sup- } \\
\text { port stand CSP }\end{array}$ \\
\hline
\end{tabular}

in the long-term as the storage technology matures. Table 7 thus presents the solar aided power generation migration analysis.

\section{Conclusions and recommendations}

Technology roadmaps have increasingly become useful for policy- and decision-makers in informing and promoting technological transitions and integration. This paper provides a step towards engaging with the relevant stakeholders to promote the integration of solar aided power generation. This was done by: (i) reviewing the literature to examine the concept of roadmapping, the approaches utilised in roadmapping, and the extent to which it has been utilised in the development of energy roadmap; (ii) developing a conceptual framework, which provided the basis for understanding how the current roadmapping practice relates to the governance of systems innovation, and it also formed the basis for supporting the analysis and accounted for the three main questions in technology roadmapping; and (iii) practical application of the conceptual framework to the case study - solar aided power generation. Solar aided power generation has a potential of combining the benefits of both renewable energy and fossil fuel electricity generation. At this stage, there are few countries that have adopted the technology globally. The solution is a feasible one in South Africa, and policy support to incorporate the technology in the REIPPPP or the PPP of National Treasury is essential.

This paper is not without limitations. Firstly, due to time limitations, it was not possible to engage with all stakeholders in the energy space and capture their perspectives with regards to this technology. What is captured in the paper was based on the literature review, as well as group discussions with some individuals. It would thus be essential to engage more with some of the potential stakeholders identified in the stakeholder analysis.

It should also be noted that solar aided power generation is only feasible in the short- to medium- term. It is not a way of continuing to generate electricity from coal, but should be seen as a strategy to introduce solar thermal technologies given that these technologies are currently not cost-effective and have low efficiencies; yet, they have environmental benefits. Taking a holistic sustainability view, solar aided power generation is thus recommended in the short- to medium-term.

\section{References}

Amer, M. \& Daim, T. U. (2010). Application of technology roadmaps for renewable energy sector. Technological Forecasting and Social Change, 77, 1355-1370.

Bakos, G. C. \& Tsechelidou, C. (2013). Solar aided power generation of a $300 \mathrm{MW}$ lignite fired power plant combined with line-focus parabolic trough collectors field. Renewable Energy, 60, 540-547.

Blignaut, J. N., Mabugu, R. M. \& Chitiga-Mabugu, M. R. (2005). Constructing a greenhouse gas emissions inventory using energy balances: the case of South Africa. Journal of energy in Southern Africa, 16, 105-116.

Carvalho, M. M., Fleury, A. \& Lopes, A. P. (2013). An overview of the literature on technology roadmapping (TRM): Contributions and trends. Technological Forecasting and Social Change, 80, 1418-1437.

Cavallaro, F. \& Ciraolo, L. (2005). A multicriteria approach to evaluate wind energy plants on an Italian island. Energy Policy, 33, 235-244.

Cowan, K. R. \& Daim, T. (2009). Comparative technological road-mapping for renewable energy. Technology in Society, 31, 333-341.

Daim, T., Yates, D., Peng, Y. \& Jimenez, B. (2009). Technology assessment for clean energy technologies: The case of the Pacific Northwest. Technology in Society, 31, 232-243.

De Piante Henriksen, A. (1997). A technology assessment primer for management of technology. International Journal of Technology Management, 13, 615-638.

Department of Energy (2010). Digest of South African energy statistics 2009. Available online: www.ener- 
gy.gov.za/files/.../2009\%20Digest\%20PDF\%20version.pdf.

Department of Energy (2013). Integrated resource plan for electricity 2010 - 2030. Available online: http://www.doeirp.co.za/content/IRP2010_updatea.pdf [accessed 4 September 2014].

Galvin, R. (1998). Science roadmaps. Science, 280, 803.

Gerdsri, N. \& Kocaoglu, D. F. (2007). Applying the Analytic Hierarchy Process (AHP) to build a strategic framework for technology roadmapping. Mathematical and Computer Modelling, 46, 10711080.

Geum, Y., Lee, S. \& Park, Y. (2014). Combining technology roadmap and system dynamics simulation to support scenario-planning: A case of car-sharing service. Computers \& Industrial Engineering, 71, 37-49.

Hu, E., Yang, Y., Nishimura, A., Yilmaz, F. \& Kouzani, A. (2010). Solar thermal aided power generation. Applied Energy, 87, 2881-2885.

Huang, L., Zhang, Y., Guo, Y., Zhu, D. \& Porter, A. L. (2014). Four dimensional Science and Technology planning: A new approach based on bibliometrics and technology roadmapping. Technological Forecasting and Social Change, 81, 39-48.

Hutchby, J. A. (2014). A 'Moore's Law'-like approach to roadmapping photovoltaic technologies. Renewable and Sustainable Energy Reviews, 29, 883-890.

InternationaL Energy Agency (2010). Energy technology roadmaps: a guide to development and implementation. Available online:

http://www.energy.gov.za/files/SETRM/EnergyTechRo admaps/Roadmap-guide.pdf [accessed 4 September 2014].

Jeffrey, H., Sedgwick, J. \& Robinson, C. (2013). Technology roadmaps: An evaluation of their success in the renewable energy sector. Technological Forecasting and Social Change, 80, 1015-1027.

Kamtsiou, V. (2014). Conceptual framework for roadmapping. Available online: http://www.cream.eu/wp-content/uploads/2014/04/CReAM_D1.1.pdf [accessed 4 September 2014].

Konnola, T. (2007). Industry dynamics and technological roadmaps in international RD \& D management. Available online: http://iri.jrc.es/concord-

2007/papers/strand6/Konnola.pdf [accessed 5 September 2014].

Li, X., Zhou, Y., Xue, L. \& Huang, L. (2014). Integrating bibliometrics and roadmapping methods: A case of dye-sensitized solar cell technology-based industry in China. Technological Forecasting and Social Change.

McDowall, W. (2012). Technology roadmaps for transition management: The case of hydrogen energy. Technological Forecasting and Social Change, 79, 530-542.

Pesonen, H.-L. \& Horn, S. (2014). Evaluating the climate SWOT as a tool for defining climate strategies for business. Journal of Cleaner Production, 64, 562-571.

Phaal, R., Farrukh, C. J. P. \& Probert, D. R. (2004). Technology roadmapping-A planning framework for evolution and revolution. Technological Forecasting and Social Change, 71, 5-26.

Phaal, R. \& Muller, G. (2009). An architectural framework for roadmapping: Towards visual strategy. Technological Forecasting and Social Change, 76, 39-49.

Pierce, W., Gauché, P., Von Backström, T., Brent, A. C. \& Tadros, A. (2013). A comparison of solar aided power generation (SAPG) and stand-alone concentrating solar power (CSP): A South African case study. Applied Thermal Engineering, 61, 657-662.

Postma, T. J. B. M. \& Liebl, F. (2005). How to improve scenario analysis as a strategic management tool? Technological Forecasting and Social Change, 72, 161-173.

REN21 (2014). Renewables 2014: global status report. Available on: http://www.ren21.net/ [Accessed 3 September 2014].

Robinson, D. K. R. \& PROPP, T. (2008). Multi-path mapping for alignment strategies in emerging science and technologies. Technological Forecasting and Social Change, 75, 517-538.

Saritas, O. \& Aylen, J. (2010). Using scenarios for roadmapping: The case of clean production. Technological Forecasting and Social Change, 77, 1061-1075.

Tran, T. A. (2007). Review of methods and tools applied in technology assessment literature. PICMET Proceedings, 5-9 August, Portland, Oregon, USA..

Winebrake, J. J. (2003). Alternative energy assessment \& implementation reference book, Lilburn, GA, Fairmont Press.

Zhang, X., Fan, J.-L. \& Wei, Y.-M. (2013). Technology roadmap study on carbon capture, utilization and storage in China. Energy Policy, 59, 536-550.

Received 1 November 2014; revised 13 September 2015 